Cibie Bluth con Ministerio de Agricultura (1996): Corte de Apelaciones de SanTIAGO de 25 de mayo de 1996 (Amparo Económico), en: GJ No 192 (1996), pp. 24-36.

Pescadores Artesanales, Asociación Gremial de Pequeños Armadores y Tripulantes Italmar A.G. y otros con Subsecretario de Pesca (s) y Directora Nacional de Pesca (2007): Corte Suprema de 21 de junio de 2007 (recurso de protección), en RDJ Tomo CIV, sección quinta, pp. 616-624.

Requerimiento de inaplicabilidad por inconstitucionalidad presentado por Silvia Peña Wasaff respecto del artículo 38 ter de la Ley $N^{o}$ 18.933, conocida como Ley de Isapres, en recurso de protección contra Isapre ING Salud S.A., Rol de Ingreso No 4972-2007, de la Corte de Apelaciones de Santiago. Tribunal ConstituCIONAL 26 de junio de 2008 (requerimiento de inaplicabilidad), Rol No 9762007, en www.tribunalconstitucional.cl

Requerimiento de inaplicabilidad de María Angélica Valenzuela Márquez, respecto del artículo 38 ter de la Ley $N^{\circ} 18.933$, en recurso de protección $N^{o} 9451-2008$ en Corte de Apelaciones de Santiago. Tribunal Constitucional 20 de abril de 2010 (requerimiento de inaplicabilidad), Rol No 1273-2008, en www. tribunalconstitucional.cl 

Estudios Constitucionales, Año 11, № 2, 2013, pp. 425 - 450.

ISSN 07180195

Centro de Estudios Constitucionales de Chile Universidad de Talca

"El influjo del principio de laicidad en el constitucionalismo colombiano"

Leonardo García Jaramillo

\title{
EL INFLUJO DEL PRINCIPIO DE LAICIDAD EN EL CONSTITUCIONALISMO COLOMBIANO*
}

\author{
INFLUENCE OF LAICISM IN COLOMBIAN CONSTITUTIONALISM
}

\author{
LEONARDO GARCÍA JARAMILLO**2 \\ Universidad EAFIT-Medellín - Colombia \\ lgarciaj@eafit.edu.co
}

RESUMEN. Sin atisbo de exageración puede afirmarse que Colombia es uno de los países de la región en los cuales mayores efectos, a nivel judicial, pedagógico y doctrinario, ha tenido la internacionalización del derecho constitucional. Desde la expedición de la Constitución de 1991 sobre todo ha habido un marcado influjo de planteamientos jurídico-politicos trasnacionales, debido a la necesidad de responder al desafio de implementar la normativa constitucional, en el contexto del pluralismo, la libertad y la dignidad como principios nodales del ordenamiento. Uno de los principales planteamientos, de los cuales sin embargo no hay análisis actualizados, es el principio de laicidad como fundamento y orientación del control constitucional. Este artículo presenta una narrativa de los casos donde la Corte Constitucional se ha valido del principio de laicidad en su labor judicial.

ABSTRACT. Without hesitation it could be said that Colombia is one of the Andean countries in which more theoretical, judicial, and pedagogical effects have had the internationalization of constitutional law. Most of all since the enactment of the Constitution in force, in 1991, had been a marked influence of transnational juridical and political approaches. This is due to the necessity of providing a suitable response toward the challenge of enforce constitutional normativity within a legal system characterized by the respect to the pluralism, the liberty and the human dignity as nuclear principles. One of the mains approaches is the laicism as a foundation and orientation of judicial review. This article aims to show a narrative of the case-law where the Constitutional Court has used the laicism principle in its ordinary work.

PALABRAS CLAVE: Laicidad, derecho constitucional, jurisprudencia, pluralismo, estado de derecho.

KEY WORDS: Laicism, constitutional law, case-law, pluralism, rule of law..

\footnotetext{
* Este artículo presenta resultados de la investigación desarrollada en el marco de la "Cátedra Benito Juárez" del Instituto de Investigaciones Jurídicas de la Universidad Nacional Autónoma de México (UNAM), con apoyo del Instituto Iberoamericano de Derecho Constitucional. Los coordinadores de la investigación son Pedro Salazar Ugarte y Pauline Capdevielle. Agradezco a los coinvestigadores amigos por el intercambio epistolar sobre algunas de las cuestiones desarrolladas, particularmente: Julieta Lemaitre, Miguel Carbonell, Pierluigi Chiassoni, Roberto Saba, Marcelo Alegre y Rodolfo Vázquez. Trabajo recibido el 11 de junio y aprobado el 16 de octubre de 2013.

** Profesor, programa de Ciencias Políticas, Universidad EAFIT-Medellín; Profesor visitante, Instituto Tecnológico Autónomo de México (ITAM); Abogado con estudios en Filosofía; Magíster en Humanidades, con énfasis en estudios políticos.
} 


\section{INTRODUCCIÓN. LAS EXPRESIONES DEL "DERECHO CONSTITUCIONAL DE LA RELIGIÓN”}

"Lentamente, humanamente, nos están reconociendo esa diversidad del pueblo colombiano y ante esa diversidad (...) cada uno podemos tener nuestros dioses. En eso nos compaginamos, creo que Dios no es solamente para unos, sino de cada uno de acuerdo a nuestras creencias". Lorenzo Muelas ${ }^{1}$

Con importantes similitudes a los procesos de reforma institucional acontecidos en Europa, y siguiendo también la tendencia de separar la Iglesia del Estado que se desarrolló en Estados Unidos -sobre todo durante la Corte Warren (1953-1969)²_, entre los cambios afines que se proclamaron en varios países en América Latina desde inicios de la década de 1990, se destaca la superación de la adscripción de los Estados como confesionales y la adopción de una correlativa separación entre la Iglesia y el Estado, dotando de mayor consideración pública al pluralismo religioso respecto de las funciones de los organismos del Estado y las competencias y prerrogativas atribuidas a la iglesia católica, tradicionalmente dominante como depositaria de la fe de los pueblos latinoamericanos (Hamburger, 2004).

Un aspecto transversal a las reformas constitucionales realizadas en América Latina es la nueva perspectiva sobre la nacionalidad, al procurar conseguir la unidad alrededor del pluralismo y reconocerlo como uno de los caracteres propios y distintivos de la condición civil latinoamericana. En este punto se articula la superación del confesionalismo como guía del Estado (Carbonell, García, 2010). Si bien ha acontecido en occidente un tránsito de los Estados teístas o confesionales hacia los Estados laicos, el proceso paulatino de secularización no ha implicado una total ausencia de la religiosidad en los textos constitucionales. Las referencias a Dios, lejos de ser una etapa superada, es una posible variante cultual del Estado Constitucional. Son expresión de lo que Häberle denomina el "derecho constitucional de la religión".

Es similar la cultura religiosa de los Estados constitucionales latinoamericanos al invocar la figura o la protección de Dios en los preámbulos de las constituciones de distintas formas, pero se consagraron igualmente la libertad de cultos, el

\footnotetext{
1 Lorenzo Muelas, miembro de la Asamblea Nacional Constituyente por los indígenas. Frase citada en las sentencias C-350 de 1994 y T-332 de 2004.

2 Dentro de las principales antologías de las decisiones de la Corte Suprema sobre la separación entre iglesia y Estado, se encuentra Alley (1999).
} 
principio de libertad religiosa y la máxima de la separación entre la Iglesia y el Estado, lo cual hace a los Estados latinoamericanos en general no teístas ni ateos, sino laicos. Se reconocen las diversas formas de religiosidad y espiritualidad, como expresa el Preámbulo de la Constitución ecuatoriana. La alta intensidad valorativa de los preámbulos de las constituciones, históricamente ${ }^{3}$ como lo estudia Häberle (2008), suelen incluir de diferentes modos y con distintas intensidades adscripciones a Dios o "verdades de fe".

El fundamento de esta forma de Estado no sólo es la igualdad de todos los ciudadanos, la garantía de los derechos sin configuraciones relativas a alguna fe particular, sino también la soberanía popular y la protección de las creencias de las minorías. El neoconstitucionalismo latinoamericano es entonces laico porque aun consagrándose a la figura de Dios, reconoce la libertad religiosa, aunque hay variaciones de grado pues, de un lado, algunas constituciones conservan algún rasgo confesional ${ }^{4} \mathrm{y}$, de otro, hay también constituciones que reconocen la separación entre Iglesia y Estado (Burleigh, 2005).

El proceso de secularización que se ha venido viviendo en Europa también se ha reflejado en América Latina (Norris e Inglehart, 2004). De una sociedad profundamente identificada con las creencias y los valores cristianos, y sus instituciones eclesiásticas, se ha asistido a un cambio sociocultural importante encaminado hacia la necesidad de establecer la cultura política y orientar el fundamento y norte ideológicos de los organismos del Estado, sobre principios y valores seculares, o laicos. Las religiones, y muy en particular la religión católica, han perdido paulatinamente el poder que ostentaron en todas las esferas del poder público, en particular en Colombia durante los 107 años de vigencia de la Constitución de 1886 (Barreto, 2011). La tradición religiosa imperante asumía un modelo de Estado confesional, toda vez que la religión católica se establecía como oficial.

\footnotetext{
3 Así, las constituciones "gustan remitir a realidades previas (ontológicas) como Dios o Cristo (por ejemplo, Australia, 1900, Indonesia 1945, Argentina 1853) o las invocan (por ejemplo, Irlanda 1937)”. (HÄBERLE (2003), p. 275).

4 "El Gobierno federal sostiene el culto católico apostólico romano" (Argentina); "la religión católica es la del Estado" y se restringe la libertad de cultos a que no se oponga a la moral universal y a las buenas costumbres (Costa Rica); y "la religión católica es la de la mayoría de los panameños” y se limita la libertad de cultos al respeto a la moral cristiana y al orden público" (Panamá). La Constitución peruana señala que "Dentro de un régimen de independencia y autonomía, el Estado reconoce a la Iglesia Católica como elemento importante en la formación histórica, cultural y moral del Perú, y le presta su colaboración".

5 Tal es el caso de las constituciones colombiana, boliviana, brasileña, ecuatoriana, mexicana, nicaragüense, paraguaya y venezolana.
} 
Para la Constitución de 1886, Dios era la fuente suprema de toda autoridad y la religión católica era la de la Nación. La religión era esencial, conjuntamente con la lengua y la autoridad, para mantener el orden social. De ahí la reafirmación de la confesionalidad religiosa colombiana como medio para alcanzar la paz, que se realizó luego de la violencia y la dictadura militar de Rojas Pinilla con el plebiscito de 1957, en el cual se le consultó al pueblo por la ratificación de los acuerdos entre los partidos políticos Liberal y Conservador que dieron origen al Frente Nacional y los cuales ratificaron, como base de afianzamiento de la comunidad nacional, el reconocimiento de que la religión Católica, Apostólica y Romana era la de la Nación. La moral cristiana limitaba la libertad de cultos (Constitución de 1886, artículo 53).

La promulgación de la Constitución de 1991 implicó el descenso en la preeminencia que la Iglesia Católica tuvo como única fe amparada por el Estado, lo cual no sólo ejerció efectos simbólicos en tanto religión oficial, sino también profundos efectos prácticos a nivel jurídico, cultural y político. En 1991 se invocó la protección de Dios, pero no se estableció ninguna referencia a una religión específica ni se le confirió atributo alguno como fuente de autoridad o de dignidad (sentencia C-350 de 1994). A partir de la interpretación sistemática de diversas disposiciones constitucionales, se deriva con claridad la naturaleza laica del Estado colombiano a partir de la promulgación de la Constitución hoy vigente.

Sin embargo, más que a la consagración misma de principios y derechos en la Constitución, el determinante influjo del principio de laicidad en el ordenamiento jurídico colombiano se debe a la renovación en las prácticas jurisprudenciales. Es decir, la inclusión en el texto constitucional de disposiciones de derecho fundamental es un presupuesto de su efectividad, pero la garantía en sí misma es deudora del rol comprometido que ha llevado a cabo la Institución a la que en 1991 se le confió la guarda de la integridad y supremacía de la Constitución. En efecto, la interpretación que ha realizado la Corte de las disposiciones constitucionales pertinentes, tanto en exámenes de constitucionalidad como en acciones de tutela que han interpuesto ciudadanos a quienes se les han vulnerado derechos fundamentales en casos concretos, ha implicado la reivindicación del principio de laicidad como orientación de la política pública y el accionar institucional.

El pluralismo y la libertad religiosa se encuentran en la base de la democracia constitucional. Desde la Asamblea Nacional Constituyente, al deliberarse sobre la eliminación en el preámbulo del carácter oficial de la religión católica y el deber que para los organismos del Estado surge de la garantía personal que comporta la disposición del artículo 19 constitucional, se estableció que la libertad de con- 
ciencia es uno de los aspectos fundamentales del nuevo ordenamiento constitucional, que entre todas las religiones hay plena igualdad, que cada persona tiene un derecho a profesar libremente su religión en forma individual o colectiva y que todas las iglesias son igualmente libres ante la ley (Gaceta Constitucional No 82, 25 de mayo de 1991, p. 10). Conforme al referido artículo 19: "Se garantiza la libertad de cultos. Toda persona tiene derecho a profesar libremente su religión y a difundirla en forma individual o colectiva. Todas las confesiones religiosas e iglesias son igualmente libres ante la ley".

La Constitución insertó en la realidad jurídico-constitucional colombiana un amplio catálogo de derechos, pero fue la jurisprudencia constitucional la que permitió que entrara en vigor. A partir de la labor de la Corte en el amparo de derechos es que las provisiones contenidas en ellos se han convertido en garantías. La histórica concepción de una Constitución como un texto de referencia o principio general para la elaboración de las leyes de menor jerarquía y que sólo consagraba un catálogo simbólico de garantías, ha trascendido en Colombia y muchos países de la región hacia una concepción donde los tribunales constitucionales pueden, y deben, crear y desarrollar el derecho, labor que han desempeñado mediante una novedosa y creativa jurisprudencia, dentro de la cual la recepción del principio de laicidad se cuenta como uno de sus principales ejemplos. La laicidad comporta fundamentalmente la separación entre el Estado y las iglesias, por lo cual sus principales elementos son: el no establecimiento de una religión oficial y, más aún, la neutralidad de los organismos del Estado en materia de adscripción a confesión religiosa alguna. Hay igualmente un respeto por la libertad religiosa y una alta consideración al trato igualitario hacia las distintas confesiones.

\section{El PRINCIPIO DE LAICIDAD EN LA JURISPRUDENCIA CONSTITUCIONAL}

En este artículo se adopta el sentido más usual del concepto "laicidad" omitiendo intencionadamente alguna (¿estéril?) discusión político-analítica acerca de sus diferencias y similitudes con otros conceptos como laicismo o secularismo. Este sentido alude fundamentalmente, a mi juicio, a dos cuestiones, una directamente relacionada con el derecho fundamental a la igualdad y otra con el principio de neutralidad. Conforme a lo primero, las personas no pueden recibir trato desigual alguno debido a su confesionalidad o a la falta de ella. De igual forma, el Estado no puede privilegiar una determinada religión así sea la suscrita por la mayoría de su población, toda vez que todas las religiones reconocidas por el Estado deben recibir igual consideración y respeto. Conforme al segundo, los organismos estatales no pueden vincularse con alguna religión o con una particular práctica que 
implique que se identifica con ella. El principio de neutralidad implica asimismo que, como evidencia la jurisprudencia constitucional, ni las iglesias pueden tener injerencia en las cuestiones propias del Estado ni el Estado puede interferir en el curso normal del desarrollo de las prácticas tradicionales de cada iglesia, lo cual implicaría afectar el derecho fundamental de libertad religiosa.

A partir de varias disposiciones constitucionales se puede caracterizar como laico al Estado colombiano. El establecimiento de la soberanía popular y la protección de las minorías, así como la consagración de una sociedad democrática, pluralista y participativa, fundada en el respeto de la dignidad humana, que asegura entre otros principios y derechos: la vida, la convivencia, la justicia, la igualdad, la libertad y la paz (Preámbulo y art. $1^{\circ}$ ); la incorporación del modelo ideológico del Estado social y democrático de derecho (art. 10); la imposición a las autoridades públicas del deber de proteger las creencias de los residentes en el país (art. $2^{\circ}$ ); el reconocimiento y la protección de la diversidad cultural y étnica de la nación (art. 7o); la libertad y la igualdad ante la ley y el hecho de que todas las personas deben recibir la misma protección y trato de las autoridades y gozarán de los mismos derechos, libertades y oportunidades sin ninguna discriminación por razones de sexo, raza, origen nacional o familiar, lengua, religión, opinión política o filosófica (art. 13); la garantía a la libertad de conciencia y el aseguramiento de que nadie será molestado por razón de sus convicciones o creencias ni compelido a revelarlas ni obligado a actuar contra su conciencia (art. 18); la garantía a la libertad de cultos según el cual toda persona tiene derecho a profesar libremente su religión y a difundirla en forma individual o colectiva y todas las confesiones religiosas e iglesias son igualmente libres ante la ley (art. 19), y la garantía a toda persona la libertad de expresar y difundir su pensamiento y opiniones (art. 85). La Constitución señaló unos lineamientos que con claridad la Corte ha interpretado en casos concretos, a partir de los cuales ha creado y consolidado estándares para la evaluación de la conformidad constitucional que deben tener medidas legislativas y políticas respecto de la laicidad estatal.

En el proceso de convertir en verdaderas garantías ciudadanas las disposiciones constitucionales, ha sido esencial el rol desempeñado por la Corte Constitucional. En efecto, a su jurisprudencia se le adeuda que en éste como en muchos otros casos las disposiciones generales y abstractas de la Constitución hayan ejercido efectiva influencia en la política pública. Con rigor político e ideológico la Corte ha retirado del ordenamiento jurídico por inconstitucionales una serie de medidas que consagran algún tipo de prerrogativas injustificadas a favor de la iglesia católica, las cuales alteran la igualdad entre las confesiones religiosas y la relación establecida 
en 1991 entre el Estado y la Iglesia. El influjo del principio de laicidad como mecanismo de control constitucional, conforme al cual la Corte ha tomado una serie de decisiones que han despertado polémica debido a la histórica adscripción a la religión católica, puede reconstruirse a partir de las siguientes sentencias.

En la sentencia T-352 de 1997 (M.P.: Eduardo Cifuentes) se revisó un fallo de tutela interpuesto por la iglesia cristiana "La Casa sobre la Roca" contra la Dirección de Impuestos y Aduanas Nacionales (DIAN). Si bien las asociaciones religiosas no son contribuyentes del impuesto sobre la renta, no están obligadas a presentar declaración de renta, ni son sujetos pasivos de retención, deben presentar una declaración de ingresos y patrimonio para establecer la información necesaria para determinar el valor de los activos, pasivos, patrimonio, etc. La DIAN obligaba a esta iglesia a presentar declaración de ingresos y patrimonio; obligación que no recaía sobre la iglesia católica. El trato diferenciado no supera ninguno de los requisitos del examen de igualdad, toda vez que no buscaba un interés público o constitucional imperioso, por lo que se torna discriminatorio. La Corte tuteló el derecho a la igualdad de la iglesia cristiana y resolvió extender a todas las confesiones religiosas el beneficio que tenía la iglesia católica de no prestar declaración de ingresos para efectos del impuesto de renta ni de patrimonio.

En otro caso sobre igualdad en las prerrogativas tributarias la Corte revisó, en sentencia T-700 de 2003 (M.P.: Rodrigo Escobar) ${ }^{6}$, un fallo de instancia que se tomó a favor de un pastor de la Iglesia de Dios Pentecostal que interpuso una acción de tutela contra el Concejo de San Joaquín, en el Departamento de Santander, por la violación de sus derechos a la igualdad y a la libertad religiosa. El Consejo exoneró del impuesto predial a la Iglesia Católica, pero negó la solicitud de exoneración a la Iglesia de Dios Pentecostal. En este como en otros casos la Corte utilizó un test integrado. Por un lado, desde la proporcionalidad, se identifican las diferentes etapas del examen, y desde el juicio de igualdad, se utilizan diferentes niveles de análisis según el caso.

Se encontró una distinción con base en una diferencia religiosa, lo cual es en sí mismo sospechoso, y una limitación en el ejercicio de un derecho constitucional a un determinado grupo de personas. La exención diferencial del impuesto predial afecta a las distintas iglesias en su libertad para difundir el culto en condiciones de igualdad. En este caso el trato entre las iglesias es desigual y, al no perseguirse un objetivo constitucionalmente imperativo, constituye una vulneración efectiva del derecho a la igualdad. La Corte ha sostenido que el equilibrio fiscal y las metas

${ }^{6}$ La Corte recurrió en sustento al precedente de la sentencia T-352 de 1997. 
fiscales gubernamentales -el argumento del Consejo para fundamentar el trato distintivo- no son, si se toman en abstracto, elementos suficientes de razonabilidad en el análisis de proporcionalidad de las medidas del Estado (sentencias C-122 de 1997 y C-1064 de 2001). La falta de razonabilidad de la distinción tributaria entre las dos iglesias constituye un fundamento suficiente para probar que el Concejo vulneró el derecho a la igualdad entre las confesiones religiosas. La Corte, además, reafirmó que la igual libertad en cuanto a las condiciones de ejercicio del culto es una condición necesaria para preservar el pluralismo religioso.

La sentencia C-1175 de 2004 (M.P.: Humberto Sierra Porto) resolvió una acción pública de inconstitucionalidad contra un aparte del artículo 152 del Decreto-Ley No 1.355 de 1970 "Por el cual se dictan normas sobre policía". Conforme a este artículo, además de un experto en cine, un abogado, un psicólogo y un representante de la asociación de Padres de Familia, al Comité de Clasificación de Películas lo debía integrar un representante de la Curia Arquidiocesana de Bogotá. Este Comité restringe la libertad de expresión al controlar de manera previa las películas que pueden distribuirse y difundirse, conforme a la prelación de la protección especial de la población menor de edad.

A juicio de la Corte, la participación obligatoria de un miembro de la curia católica en el Comité de Clasificación de Películas no resiste la aplicación del test de igualdad ${ }^{7}$, porque no puede establecerse un fin constitucional. La norma sencillamente privilegia la participación en una instancia estatal de toma de decisiones de la perspectiva del orden social y moral de la confesión religiosa católica, lo cual resulta inaceptable de conformidad, tanto con el artículo 19 constitucional del cual se deriva la prohibición de toda prerrogativa a alguna confesión religiosa, como con la Ley No 133 de $1994^{8}$, que por su carácter de estatutaria constituye un parámetro de constitucionalidad de las leyes ordinarias (artículos 152 y 153 constitucionales). Resulta inaceptable adicionalmente con la normativa que establece la naturaleza pluralista del Estado que se garantiza a partir del respeto a los principios de igualdad, libertad y convivencia. La participación como elemento esencial de la forma democrática por la que se optó en la Constitución de 1991, es un principio que se debe ponderar con otros igualmente importantes, como son el pluralismo, la igualdad y la tolerancia.

\footnotetext{
7 Para una versión desarrollada del test de igualdad, véase la sentencia C-152 de 2003.

8 En particular con sus 10 primeros artículos. Esta ley desarrolla el derecho de libertad religiosa y de cultos, reconocido en el artículo 19 constitucional.
} 
Respecto a la igualdad entre las confesiones religiosas, así como al derecho fundamental a la libertad de cultos9, la sentencia T-376 de 2006 (M.P.: Marco Gerardo Monroy) resolvió el caso de un interno en la Penitenciaria de La Dorada, en el Departamento de Caldas, feligrés de la Iglesia Pentecostés Unida Internacional, a quien las directivas de la Institución le vulneraron sus derechos porque hicieron caso omiso de varias solicitudes para que, en el patio en el que cumple su condena, se adecuara un lugar apropiado para desarrollar sus actividades religiosas. En el mismo patio hay otras tres congregaciones distintas por lo que el espacio destinado a estas actividades se volvió insuficiente. La Corte, al probar la afectación en un derecho fundamental y que dicha iglesia aparece inscrita en el Registro Público de Entidades Religiosas, resolvió conceder la tutela para la protección de la libertad religiosa y de cultos del interno. Ordenó, en consecuencia, al director de la penitenciaria que asigne en circunstancias de igualdad un espacio de tiempo y lugar para desarrollar las actividades religiosas propias de la iglesia.

La Corte ha decidido que no se pueden otorgar tratos discriminatorios que privilegien una determinada religión sobre otras. En este sentido fue consistente con sus precedentes cuando declaró inexequible, en sentencia C-817 de 2011 (M.P.: Luis Ernesto Vargas), la Ley No 1.402 de 2010 que asociaba la Nación con la celebración de los 50 años de la diócesis de El Espinal, Tolima, y declaraba a su catedral monumento nacional. Honraba así la ley un fenómeno exclusivo de la religión católica. Se reafirmó en la sentencia el deber de neutralidad del Estado y su naturaleza laica, así como la normativa principialista y axiológica de la Constitución conforme a la cual a las instituciones del poder público no les está permitido otorgar ningún tipo de trato preferente a una religión en particular. No pueden identificarse formalmente con una iglesia ni realizar actos oficiales de adhesión a una religión. Esta sentencia constituye la aplicación hasta el momento más estricta del test que ha erigido la Corte para mantener la separación entre la Iglesia y el Estado. De hecho una de las principales razones de los cuatro magistrados que salvaron el voto, fue que la ley no afectaba el principio de laicidad sino que fomentaba la protección del patrimonio cultural.

La validez de normas que establecen una discriminación a favor de la religión católica y en contra de las demás, se ha solido defender a partir del carácter mayoritario de dicha confesión en la sociedad colombiana. Este argumento resulta violatorio de principios constitucionales como la dignidad humana, el pluralismo,

9 Conforme a la sentencia T-403 de 1992 las libertades de culto y expresión ostentan el carácter de derechos fundamentales de aplicación inmediata. 
la igualdad y la realización de los derechos como fin del Estado. La prevalencia del interés general y la promoción de la prosperidad general a la que se refieren, respectivamente los artículos $1^{\circ}$ y $2^{\circ}$ de la Constitución, no pueden interpretarse como si implicaran una prevalencia utilitarista del bienestar general respecto del bienestar de las minorías. Sustentar que la religión católica es mayoritaria en Colombia no hace que el trato distintivo a su favor deje de ser discriminatorio respecto de las otras confesiones religiosas. Se trata de una diferenciación de naturaleza discriminatoria porque la Constitución no admite las diferenciaciones a partir del número de feligreses, toda vez que confirió igual valor jurídico a todas las confesiones religiosas.

La sentencia C-224 de 1994 (M.P.: Jorge Arango) declaró conforme a la Constitución la expresión "moral cristiana" contenida en el artículo 13 de la Ley No 153 de 1887. El fundamento de la Corte fue que, si bien hay una separación entre el Estado y la Iglesia, hay también una interpretación de la expresión que resulta acorde con la Constitución, cual es en tanto referente a una "moral social" o "moral general". La Corte profirió un fallo modulativo ${ }^{10}$ en el cual incluyó, en la parte resolutiva de la sentencia, la interpretación de la norma que es constitucional, con lo cual ajustó el contenido de la norma a la Constitución para no tenerlo que declarar inconstitucional en su completitud sino sólo en algunas de sus posibles interpretaciones.

Si bien en puridad podría afirmarse que, al declarar constitucional la medida modulando la interpretación de la expresión, la Corte no siguió con rigor el autoprecedente sobre laicidad estatal, no desconoció el hecho sustantivo de que la confesionalidad no puede ser sustento de la comprensión jurídica de alguna disposición, máxime si se trata de las fuentes del derecho. Declaró inconstitucional cualquier interpretación de la expresión que se aleje del carácter laico del Estado. Sostuvo la sentencia, sobre la referencia a la moral cristiana, que "no implica, como pudiera pensarse, una exigencia de carácter dogmático que suponga un privilegio para esa moral frente a otras. Significa, más bien, la referencia a uno de los elementos constitutivos de la costumbre, la "opinio juris", según la cual la

10 Un fallo de constitucionalidad modulado o una sentencia modulativa se profiere cuando, en ejercicio de facultad legítima del juez constitucional, una norma se declara conforme al ordenamiento jurídico pero condicionando su interpretación a un sentido determinado. Una norma puede resultar inconstitucional en una de sus interpretaciones pero no en todas, por lo que se hace necesario proferir una decisión distinta respecto de las usuales de exequibilidad integral o inexequibilidad. En esos casos se encuentra una expresión que denota que "la norma sometida a examen constitucional es exequible en el entendido de que...". 
costumbre, para que sea jurídica, debe generar en la comunidad que la observa, la convicción de obligatoriedad" (Sentencia C-224 de 1994).

La sentencia C-094 de 2007 (M.P.: Jaime Córdoba) resolvió una acción pública de inconstitucionalidad en la que se solicitaba el examen constitucional de las expresiones "iglesia parroquial" del artículo 1022 del Código Civil y "los arzobispos y obispos" del artículo 222 del Código de Procedimiento Civil. Las expresiones se refieren a la inclusión de los arzobispos y los obispos de la Iglesia Católica dentro de las personas a quienes se les aplica el medio exceptivo para comparecer a declarar en los procesos civiles. El argumento para declarar la conformidad con la Constitución de las expresiones demandadas, es que se entiende que están incluidos también los ministros de igual jerarquía de otras religiones reconocidas por el Estado.

En sentencia C-478 de 1999 (M.P. (E): Martha Victoria Sáchica) se profirió un fallo modulativo al declarar la constitucionalidad de la expresión "por las autoridades eclesiásticas" contenida en la ley que reglamenta el servicio de Reclutamiento y Movilización, pero en el entendido de que se refiere no sólo a la autoridad eclesiástica católica sino a cualesquiera iglesias o confesiones religiosas reconocidas por el Estado. Esta norma consagra como causal de aplazamiento del servicio militar obligatorio haber sido aceptado o estar cursando estudios para la carrera sacerdotal en establecimientos reconocidos por autoridades eclesiásticas.

A partir del principio de igualdad se han extendido a otras iglesias beneficios de los que sólo gozaba la Iglesia Católica. En la sentencia C-609 de 1996 (Ms. Ps.: Alejandro Martínez, Fabio Morón) se declaró constitucional el testimonio por certificación jurada de Cardenales y Obispos, consagrado en el Decreto 2700 de 1991, art. 287, pero en el entendido que dicho trato especial abarca también a miembros de igual rango de otras iglesias reconocidas por el Estado.

La sentencia T-421 de 1992 (M.P.: Alejandro Martínez) reconoció el derecho a la libertad religiosa de los padres de un menor para brindarle la educación religiosa que consideraban adecuada. Prohibió a un establecimiento público educativo impartir educación religiosa y hacer comparecer a sus rituales al menor. "(L)as instituciones educativas oficiales deben mantener una posición neutral y preguntarle al educando -o a sus padres si es menor-, al momento de la matrícula, acerca de si desea estudiar o no la asignatura de religión, sin indagar si en efecto profesa o no dicho credo".

La sentencia C-088 de 1994 (M.P.: Fabio Morón), en la cual la Corte ejerció el control automático de constitucionalidad del proyecto de ley estatutaria que desarrolla el derecho a la libertad religiosa y de cultos consagrado en el artículo 19 
constitucional, siguió criterios de constitucionalidad establecidos en la Ratio de la C-027 de 1993. Sobre la cuestión educativa reiteró el derecho de toda persona a elegir para sí, los padres para los menores o los incapaces bajo su dependencia, la educación religiosa y moral según sus propias convicciones dentro y fuera del ámbito escolar. Asimismo, sobre el tema tributario, declaró inexequible alguna normativa del proyecto de ley que establecía una franquicia postal para impresos y correos de las iglesias y confesiones religiosas y la posibilidad de recibir exenciones tributarias de la Nación y de las entidades territoriales. El fundamento fue que este tipo de exenciones tributarias es de iniciativa gubernamental y ese requisito no se había cumplido en esta ocasión. Declaró constitucional no obstante otra norma del mismo proyecto que, desde el respeto al principio de igualdad, dejaba en libertad a los municipios para conceder exenciones tributarias a las iglesias.

También abordó la C-088 de 1994 el reconocimiento de la personería a la iglesia católica, el cual no viola la igualdad porque otras iglesias pueden asimismo realizar acuerdos con el Estado colombiano para establecer mecanismos de regulación jurídica, tal como se hizo con el Convenio de Derecho Público entre la Iglesia Adventista del Séptimo Día y el Estado para garantizar el ejercicio del derecho fundamental a la libertad religiosa y de cultos. Este Convenio también reconoce que, en sustitución del que establezca la ley, el descanso laboral semanal para los fieles de esta iglesia es el sábado, por lo que previo acuerdo entre las partes, comprende desde la puesta del sol del viernes hasta la puesta del sol del sábado ${ }^{11}$.

La sentencia C-568 de 1993 (M.P.: Fabio Morón) resolvió un curioso caso. En ejercicio de acción pública de inconstitucionalidad ${ }^{12}$, un ciudadano demandó la declaratoria de inconstitucionalidad de los preceptos legales que ordenan que las festividades católicas sean días festivos de descanso obligatorio (Reyes Magos, San José, Jueves Santo, Viernes Santo, Ascensión del Señor, Corpus Christi, Sagrado Corazón, San Pedro y San Pablo, Asunción de la Virgen, Día de Todos los Santos,

11 Sobre este último punto, véase, T-982 de 2001 (M.P.: Manuel José Cepeda) en la cual la Corte reguló que el día domingo no puede ser impuesto por el empleador como único día posible de descanso a trabajadores que guardan otro día como de ocio con valor religioso. Estableció esta sentencia que "las personas, en ejercicio de su libertad religiosa, tienen entre otras garantías el derecho 'de practicar, individual o colectivamente, en privado o en público, actos de oración y culto; conmemorar sus festividades, y no ser perturbados en el ejercicio de estos derechos' y, tampoco, podrán ser 'obligados a actuar contra su conciencia'. Eso implica, que cuando es parte esencial de la libertad de religión y culto la consagración de un día para la adoración de Dios, esta actividad se encuentra dentro del ámbito de protección del derecho".

12 Consagrada en el artículo 241, num. $4^{\circ}$, constitucional. 
Inmaculada Concepción y Natividad), así como los domingos. A su juicio, tales preceptos resultan violatorios de los artículos constitucionales que consagran la libertad religiosa y de cultos, el pluralismo y la protección de la diversidad étnica y cultural de la Nación. La argumentación de la acción se sintetiza, tanto en que de la sociedad colombiana hacen parte etnias y culturas que practican otras religiones, como que debido al carácter laico del Estado no debe "continuar siendo codifusor y coevangelizador al persistir ordenando por mandato de la ley la vacancia festiva para que los católicos puedan celebrar los ritos inherentes a sus conmemoraciones religiosas".

Aunque el hecho de establecer el domingo y otros días feriados como días de descanso laboral es de raigambre religioso, la Corte encontró que en la actualidad prima el elemento cultural propio de la sociedad colombiana ${ }^{13}$.

$\mathrm{Al}$ decir de la sentencia: "Los pueblos desde los primeros tiempos de su vida civilizada, han comprendido la necesidad del descanso que sigue a la actividad ordinaria, como un procedimiento de recuperación de la fuerza o energía gastada en aquélla, y como una manera de gozar de sus frutos. Pues bien, los registros de la cultura ponen de presente que esas oportunidades de descanso vinieron a coincidir con el ejercicio de prácticas religiosas. Durante la Edad Media, por ejemplo, los burgos eran sitios dedicados no sólo al mercado dominical sino también a la actividad judicial y a la práctica del culto. Lugares a los que concurrían los habitantes de una comarca, en oportunidad de vacancia, para fines de esparcimiento y en definitiva de abandono de su actividad ordinaria o regular. Ese día de mercado, característico de las sociedades europeas, así como de la práctica de nuestros pueblos andinos, por las necesidades de la población de intercambio de sus productos y, de alguna manera, para salir del aislamiento de la vida campesina, trajo como resultado que dicho día de descanso coincidiera con vacancias, que podían incorporar, según las culturas de cada comunidad, ciertas prácticas religiosas. Ni en los pueblos más primitivos, ni en la actualidad, ese día de descanso fue exclusivamente religioso" (sentencia C-568 de 1993).

13 Tal como en Estados Unidos lo fue el establecimiento de un día festivo, el 15 de enero, en conmemoración de Martin Luther King y la lucha por el movimiento de los derechos civiles. Antes esto sólo se había hecho por George Washington. Ese día de enero se convierte así en un "día de la Constitución" (HÄBERLE (2003)) que significa tanto una conmemoración al legado de King como una recordación de la importancia de la eliminación de la discriminación racial. Garantías de los días feriados como éste "están tejidas de la materia prima constitucional. Cuando el Estado constitucional festeja o 'hace' festejar, lo hace al servicio de determinados fines. $Y$ estos fines son de naturaleza fundamental, pues solamente de este modo puede legitimarse la exención del trabajo y la vida normal, el día de fiesta" (HäBerLe, 2003, p. 283). 
La Corte profirió fallo de constitucionalidad con sustento en la tradición, que se remonta a la Colonia, desde cuando la doctrina cristiana ejercía una fuerte configuración cultural, que por variables de orden económico, histórico, social y psicológico constituyeron elementos de la idiosincrasia y la cultura nacional. La definición del calendario laboral, en particular de los días feriados, no se realiza entonces de conformidad con las prácticas propias del rito católico, sino que se han constituido en un elemento propio de una consolidada tradición cultural. No resulta contrario a la libertad religiosa y de cultos el que el legislador, al diseñar el calendario laboral y los días de descanso, haya escogido días festivos de un culto religioso ${ }^{14}$. Asimismo, las normas que establecen que días festivos de la religión católica sean días feriados nacionales no son inconstitucionales, porque esta coincidencia no implica que algún ciudadano tenga la obligación de realizar las prácticas propias de dicha religión.

Hasta 1994 la República de Colombia se consagraba al Sagrado Corazón de Jesús en una conmemoración oficial anual que se realizaba en el Capitolio Nacional. La sentencia C-350 de 1994 (M.P.: Alejandro Martínez) abordó la cuestión y declaró inconstitucional el artículo de la Ley No $1^{\text {a }}$ de 1952 que le ordenaba al Presidente de la República o un representante suyo renovar cada año la consagración oficial de la República de Colombia al Sagrado Corazón de Jesús. El artículo había devenido inconstitucional con la expedición de la Constitución de 1991 debido al carácter pluralista del Estado, del cual el pluralismo religioso es uno de sus elementos más importantes, y al principio de laicidad. Sostiene la sentencia que la Constitución excluye cualquier forma de confesionalismo y consagra la libertad religiosa y el tratamiento igualitario de todas las confesiones. Reconoce de manera pionera la sentencia que la estricta neutralidad estatal en materia religiosa es la única forma de que los poderes públicos aseguren el pluralismo y la coexistencia igualitaria y la autonomía de las distintas confesiones religiosas.

La sentencia sintetizó en cinco las diversas formas como la teoría política ha presentado las relaciones Iglesia-Estado. (1) Estados confesionales sin tolerancia religiosa que establecen una religión oficial cuyos contenidos son jurídicamente obligatorios, tal como los Estados cristianos medievales. (2) Estados confesionales con tolerancia o libertad religiosas en los cuales existe una religión oficial, pero no

14 En las sentencias C-107 de 1994 y C-1261 de 2000 la Corte decidió estarse a lo resuelto por haber operado el fenómeno procesal de la cosa juzgada constitucional respecto de la sentencia C-568 de 1993. La primera examinó la constitucionalidad de una ley que trasladaba el descanso remunerado de algunos días festivos y la segunda resolvió que era constitucional un artículo de la Ley No 50 de 1990 que estableció "la obligación del empleador de dar descanso dominical a todos sus empleados". 
se rechazan las demás religiones. La existencia de una religión oficial no implica que sus contenidos normativos se vuelvan mandatos jurídicos obligatorios para todos. Las religiones diversas a la oficial son toleradas con grados variables de libertad de ejercicio. (3) Estados de orientación confesional o de protección de una religión determinada en los cuales si bien el Estado no necesariamente establece una religión oficial, procura un régimen jurídico que reconozca el hecho social e histórico del carácter mayoritario de una o más confesiones religiosas a las cuales les confiere cierta preeminencia. Ejemplos: el actual ordenamiento constitucional en España. (4) Estados laicos con plena libertad religiosa. No hay una religión oficial y los sistemas jurídicos no tienen influjo alguno de instituciones propias de alguna confesión. Existe entonces una estricta separación entre las iglesias y el Estado porque la propia consagración de la normativa constitucional de naturaleza axiológica y principialista, establece la igualdad entre todas las confesiones religiosas. Ejemplos: Estados Unidos, Francia y Turquía. (5) Estados ateos que toleran las prácticas religiosas que no se oponen con las seculares u oficiales, pero no garantizan jurídicamente la libertad religiosa ni la libertad de cultos. Se pueden presentar diversos grados de hostilidad hacia los fenómenos religiosos.

La tercera fue la forma cómo se dio la relación Iglesia-Estado bajo la Constitución de $1886^{15}$. Desde la reforma liberal del Acto legislativo 1 de 1936 se había consagrado la libertad de conciencia, pero como vimos el preámbulo de la Constitución de 1886, aprobado por el plebiscito de 1957, señalaba que una de las bases de la unidad nacional era la religión Católica, Apostólica y Romana como la de la nación, y que como tal los poderes públicos la protegerán. La Constitución de 1886 garantizaba la libertad de cultos, pero la subordinaba al culto cristiano.

La cuarta es cómo acontece bajo la Constitución de 199116. La diferencia entre el Estado laico con libertad religiosa y el ateo es que aquél reconoce el fenómeno religioso y protege la libertad de cultos sin favorecer alguna confesión religiosa en particular, pero sin negar la importancia de las distintas confesionalidades para

15 "El Constituyente de 1991 abandonó el modelo de regulación de la Constitución de 1886 -que consagraba un Estado con libertad religiosa, pero de orientación confesional por la protección preferente que otorgaba a la Iglesia Católica-, y estableció un Estado laico, con plena libertad religiosa, caracterizado por una estricta separación entre el Estado y las iglesias, y la igualdad de derecho de todas las confesiones religiosas frente al Estado y frente al ordenamiento jurídico". Sentencia C-350 de 1994.

16 En Colombia la Ley No 133 de 1994, en su artículo $2^{\circ}$, prohíbe el establecimiento de una religión oficial. Este también es el caso de Estados Unidos, cuya Constitución consagra en la Primera Enmienda la libertad de cultos y la prohibición al Congreso de establecer una religión oficial. Este también es el caso de Francia, cuya Constitución de 1958 consagra en su artículo $2^{\circ}$ que es una República indivisible, laica, democrática y social. 
miembros de la comunidad. En un Estado laico se protege entonces, al tiempo, a las personas, el pluralismo de sus ideologías y concepciones del mundo y del buen vivir, y a las diversas iglesias su autonomía y la igualdad jurídica entre ellas. "Así como el Estado se libera de la indebida influencia de la religión, las organizaciones religiosas se liberan de la indebida injerencia estatal" (sentencia C-350 de 1994).

En la sentencia C-027 de 1993 (M.P.: Simón Rodríguez) se analizó la relación entre el Estado y la Iglesia Católica conforme a las disposiciones constitucionales relevantes. La Corte acumuló varias acciones públicas que demandaban la declaratoria de inconstitucionalidad de la Ley No 20 de 1974 que aprobaba un Concordato entre Colombia y la Santa Sede ${ }^{17}$. La sentencia declaró inconstitucional parte de la normativa concordataria porque violaba la libertad religiosa y el principio de igualdad en el contexto de las iglesias y confesiones religiosas, toda vez que representaban un trato privilegiado por parte del Estado a la Iglesia Católica. El artículo 11 establecía la contribución del Estado con fondos del presupuesto nacional al sostenimiento de planteles católicos y el artículo 12 obligaba incluir en los establecimientos oficiales enseñanza y formación religiosa según el magisterio de la Iglesia.

De otra parte, declaró conforme a la Constitución: el artículo $1^{\circ}$, que declara que la religión católica es un elemento fundamental del bien común, lo cual no implica que otras confesiones religiosas también manifiesten que se ponen al servicio de esta comunidad como elemento de ventura y bienaventuranza; la excepción a prestar el servicio militar por parte de los ministros de la Iglesia Católica, en el entendido de que dicha excepción cobija también a los ministros de todas las confesiones religiosas reconocidas por el Estado, y el artículo 24 que exceptúa del pago de impuestos a los edificios de culto, curias diocesanas, casas episcopales y seminarios. En lugar de retirar la excepción tributaria la extendió a todas las iglesias porque, apuntó la sentencia, sería inequitativo exigir el cobro de tales impuestos a las iglesias que sostienen sus lugares de culto con dineros de los feligreses, puesto que éstos tributan ya por su propio patrimonio, de forma que de aceptarse el gravamen sobre los inmuebles de la respectiva congregación se estaría consagrando un doble tributo.

\footnotetext{
17 Esta ley había dejado sin efectos el Concordato suscrito en Roma el 31 de diciembre de 1887 (recién aprobada la Constitución de 1886) y aprobado por la Ley No 35 de 1888. En virtud a este Concordato la Iglesia, no sólo recobró la libertad e independencia que le habían sido menguadas con el triunfo de los liberales que proclamaron la Constitución de 1863, sino que se le atribuyeron nuevas y amplias prerrogativas en asuntos como el registro civil de las personas y la educación pública.
} 
La sentencia precisa el carácter laico, no ateo, del Estado, pues señala que con la declaratoria de inconstitucionalidad no se está afirmando que los hijos de familias católicas no puedan recibir educación religiosa. "Mas lo que se censura frente al nuevo Estatuto Constitucional, es que compulsivamente sea esa la única enseñanza que deba impartirse en los centros educativos del Estado, sin que se dé opción al alumnado de recibir la de su propia fe, o de no recibir ninguna (...). A la Iglesia Católica habrá de dársele el espacio religioso en los establecimientos del Estado, lo mismo que a las demás religiones, dejando en todo caso en libertad a los estudiantes que no quieran recibir instrucción religiosa alguna, con lo cual se conseguiría colocar en el mismo plano de igualdad a todas las confesiones pues se satisfaría el interés religioso de los estudiantes según sus propias creencias y no se obligaría a nadie a recibir cátedra religiosa" (sentencia C-027 de 1993).

En relación con los alcances y límites de la acción estatal en el desarrollo de sus funciones constitucionales y legales, la Corte ha estructurado una sólida subregla relativa al alcance de los principios de pluralismo y diversidad religiosa, y los derechos de libertad religiosa y de cultos. En la sentencia C-152 de 2003 (M.P.: Manuel José Cepeda) estableció un estándar de constitucionalidad, consistente en cinco criterios, para determinar si alguna norma vulnera en efecto los principios de pluralismo religioso y la separación Iglesia-Estado ${ }^{18}$. Para estar en conformidad con la Constitución las regulaciones religiosas no pueden: (1) establecer una religión o iglesia oficial; (2) identificar explícitamente al Estado con una determinada religión o iglesia; (3) determinar la realización oficial por parte del Estado de actos de adhesión a una religión o iglesia particular, incluso si son simbólicos; (4) determinar la toma de decisiones por parte del Estado que tenga objetivos religiosos o que expresen preferencias por alguna religión o iglesia particular; (5) adoptar políticas o acciones cuya manifestación práctica sea promover, beneficiar o perjudicar alguna religión o iglesia determinada ${ }^{19}$.

En esta sentencia C-152 de $2003^{20}$ se analizó la demanda de inconstitucionalidad contra la Ley No 755 de 2002, llamada "Ley María”, pues presuntamente desconocía principios de orden constitucional relacionados con la laicidad. Toda

\footnotetext{
18 La sentencia incluye breves pero interesantes referencias al derecho comparado (Estados Unidos, Alemania, Francia) que ilustran las formas cómo los constitucionales han establecido el influjo del principio de laicidad en la práctica de las instituciones estatales. Véase fundamento jurídico 4.4.2.

19 En esta sentencia se resolvió que denominar "Ley María” a una ley de la República expedida por el Congreso, no violaba la Constitución.

20 Esta sentencia reiteró las razones de las decisiones en las sentencias C-568 de 1993 y C-350 de 1994.
} 
vez que el título de una ley no tiene contenido normativo, la Corte empieza preguntándose si puede ser objeto de control constitucional. La respuesta afirmativa se sustenta en el valor que tiene como criterio interpretativo del articulado de la propia ley. Si una ley se titula de forma contraria a la Constitución, podría orientar una interpretación igualmente inconstitucional, por lo cual debe ser eliminado su título como cualesquiera otras expresiones de la ley.

De lo que se trata en esta sentencia, respecto del principio de laicidad, es si titular una ley como "Ley María" vulnera dicho principio, así como la normativa constitucional de pluralismo y diversidad cultural. No es admisible dispensar un trato preferente a alguna de las iglesias reconocidas por el Estado debido al principio a la igualdad, consagrado en general en el artículo 13 que prohíbe la discriminación por razones religiosas y consagrado igualmente, en particular, en el artículo 19 conforme al cual las confesiones e iglesias son igualmente libres. ¿ Se promueve entonces la religión católica al titular una ley "María"?21.

En el primer debate al proyecto de ley se propuso denominarla "Ley María" para "rendir un homenaje a las madres colombianas, a la madre eterna y a la pequeña María cuyo nacimiento ha inspirado todas las recientes manifestaciones de apoyo a este proyecto y a la defensa del derecho preferente de los niños colombianos" 22 . Toda vez, entonces, que el nombre "María" se puede asociar a la madre de Jesús, es constitucionalmente imperativo analizar si titular una ley con esta expresión vulnera el principio de laicidad y el pluralismo religioso.

En sustento de la declaratoria de constitucionalidad la Corte se valió de los criterios erigidos, por lo cual se debe analizar si el título de la ley implica la adhesión a una determinada religión, tiene una finalidad religiosa o posee una connotación religiosa única y necesaria. La respuesta afirmativa a alguna de estas tres cuestiones conllevaría a la declaratoria de inconstitucionalidad del título de la ley. La finalidad que se establezca con la norma constituye el criterio para determinar la división entre las acciones estatales constitucionalmente permitidas o prohibidas en materia religiosa.

Para responder negativamente a las tres cuestiones, la Corte afirma que, debido a que son tres los propósitos del título (homenajear a las madres, a la madre eterna

21 Se puede traer a colación la declaratoria de inconstitucionalidad del artículo $2^{\circ}$ de la Ley No $1^{\text {a }}$ de 1952 que ordenaba al Presidente de la República consagrar el país al Sagrado Corazón de Jesús (sentencia C-350 de 1994).

22 Gaceta del Congreso No 465, 19 de septiembre de 2001. "La pequeña María" era la recién nacida hija del periodista, Juan Lozano Ramírez, quien era además Consejero Presidencial para la Familia, la Mujer y la Niñez, y promovió la licencia de paternidad. 
y a una recién nacida de nombre "María"), no se verifica una ventaja a favor de determinada religión. En la sentencia se acudió en sustento a la ponencia para primer debate del proyecto de ley, pues estableció que el título no tuvo como propósito la mención a la "madre de Cristo", por lo cual el propósito del título no fue promover la fe cristiana. No se puede deducir del título una identificación formal y explícita del Estado con la religión católica. La expresión "madre eterna" no vulnera el pluralismo religioso porque no hace referencia expresa a la madre de Cristo, sino que para muchos está más bien asociado a cosmovisiones para las cuales la tierra es la madre eterna en tanto partera de todo lo existente en el planeta. Finalmente, debido a que tampoco era el fin exclusivo del título homenajear a una persona natural sino una forma de promocionar la ley a partir de su identificación con un nombre ampliamente difundido en Colombia, la Corte no encontró objeción en ese punto.

En la sentencia más reciente que recurrió en sustento del análisis constitucional al principio de laicidad, se reiteró la importancia de resguardar este principio y la normativa sobre pluralismo y libertad de cultos. Se trata de la revisión que la Corte realizó al fallo de un juez laboral del circuito de Cali, capital del Departamento del Valle del Cauca, sobre pensiones y protección de la seguridad social y del mínimo vital, en el cual se le negó una acción de tutela a un adulto mayor que solicitaba la pensión de vejez. La Corte confirmó el fallo de instancia pero, en la T-453 de 2012 (M.P.: Luis Ernesto Vargas), amonestó al juez porque incluyó referencias bíblicas en los pies de página del fallo. La sola referencia a parte alguna de un texto religioso en documentos suscritos por autoridades públicas, puede implicar que se suponga por parte de los destinatarios de la función de administrar justicia un sesgo fundado en creencias personales del juez y, así, dar una idea equivocada acerca de los criterios que rigen la función judicial.

La Corte prohibió expresamente entonces que en documentos públicos se incluyeran citas bíblicas. En sustento afirma la sentencia que en ejercicio de sus funciones las autoridades públicas están obligadas a respetar el principio de laicidad, el cual se materializa en la imposibilidad de adherir o promover determinada religión, o adoptar cualquier conducta que desconozca el pluralismo, la coexistencia igualitaria y la autonomía e independencia de las distintas confesiones religiosas.

\section{Conclusión}

De conformidad con el Informe Internacional sobre Libertad Religiosa del Departamento de Estado de los Estados Unidos, de 2012, en numerosos países 
no se protegen a las minorías contra la discriminación social y la violencia, y sigue siendo una práctica generalizada la restricción a las libertades para elegir y practicar una fe, cambiar de religión, difundir las creencias y prácticas religiosas o rechazar la religión. En el capítulo sobre Colombia del Informe se señala que la Constitución de 1991, así como leyes y políticas que se han expedido desde su promulgación, protegen la libertad religiosa y, en la práctica, el gobierno la respeta $^{23}$.

En este sentido debe reconocerse la importancia de los precedentes judiciales que han surgido de la interpretación que, en casos concretos de tutela y en casos generales de constitucionalidad, la Corte ha realizado de la normativa constitucional, sobre todo de aquélla con naturaleza de principios. El fundamento jurídico y la orientación política de estos precedentes ha sido el principio de laicidad en el contexto de un país en general religioso, pero que adoptó a nivel del texto que ocupa la cúspide de la pirámide normativa la separación entre Iglesia y Estado, así como el principio de neutralidad.

Las sentencias en las que se han fallado los casos que han recurrido en sustento al principio de laicidad, han reafirmado igualmente el valor de la coherencia en el precedente judicial. La Corte ha relacionado y armonizado la invocación constitucional a Dios, con el pluralismo estatal y su naturaleza no-confesional. Debido a que la Constitución confirió igual valor jurídico a todas las confesiones, los organismos estatales deben mantener su neutralidad en materia religiosa. Aunque la Corte reconoció que el Estado y sus autoridades deben proteger las religiones como derechos individuales y colectivos trascendentes, ha sido estricta en mantener la separación entre la Iglesia, de cualquier confesión, y el Estado.

Si bien la Constitución de Colombia no establece expresamente como laico al Estado ni refiere a conceptos como "Estado laico" o "aconfesionalidad" 24 , a partir de una interpretación sistemática de la Constitución, de sus principios y derechos (principio democrático, pluralismo, tolerancia, igualdad, dignidad y libertad de cultos), se deriva con claridad su naturaleza esencialmente laica. El

\footnotetext{
23 Fue en su momento criticado por la opinión pública el Decreto 4500 de 2006, expedido por el presidente Álvaro Uribe Vélez, que obliga a las instituciones de educación pública a dictar clases de religión.

24 Como sí lo hacen otras constituciones, como la ecuatoriana en su artículo 1 ("El Ecuador es un Estado constitucional de derechos y justicia, social, democrático, soberano, independiente, unitario, intercultural, plurinacional y laico. Se organiza en forma de república y se gobierna de manera descentralizada”.). La Constitución de Rusia igualmente lo consagra como "Estado laico" (art. 14), así como las constituciones de Francia $\left(\right.$ art. $\left.1^{\circ}\right)$ y Guinea (art. $\left.1^{\circ}\right)$.
} 
Estado colombiano es laico, mas no ateo o agnóstico ${ }^{25}$. Para la garantía y el goce efectivo de la libertad de conciencia, religión y culto, los organismos del Estado deben también proteger las actividades confesionales propias de las distintas iglesias. Con acierto señala Prieto (2008) que la auténtica laicidad no es más que el pleno ejercicio de la libertad religiosa en todas sus dimensiones.

Los límites infranqueables que ha establecido la jurisprudencia al respecto son: las funciones públicas ni se pueden basar en actividades propias de una determinada iglesia ni tampoco se pueden fusionar con las actividades propias de las instituciones religiosas; los organismos del Estado pueden promover o respaldar manifestaciones religiosas si al tiempo tienen un claro carácter de manifestación cultural para una comunidad de personas ${ }^{26}$; no es admisible incluso la práctica equitativa de programas que incentiven todas y cada una de las religiones reconocidas por el Estado, pues aunque no se favorecería así a una religión en particular, y con ello no se vulneraría el principio de igualdad, se vulnera en efecto la neutralidad que el Estado en virtud del principio de laicidad debe conservar respecto de las confesiones religiosas.

El Estado es entonces aconfesional porque no acoge como propia ni declara como oficial una determinada confesión religiosa ni sus actuaciones se inspiran en criterios religiosos particulares. Una conducta se tipifica como delito o se realiza alguna conmemoración, no por cuestiones religiosas sino, respectivamente, por deber estatal de proteger la vida o la propiedad, por ejemplo, o por celebrar alguna tradición histórica y culturalmente importante. La Corte encontró que de la neutralidad no se deriva ni un tratamiento igual a las religiones a partir de las actividades que los organismos del Estado realicen, ni un completo aislacionismo de la religión respecto de los intereses del Estado. La neutralidad resulta contraria a las actividades de patrocinio o promoción estatal de alguna religión. De la neutralidad se deriva la prohibición de que las actividades públicas tengan fundamento, sentido u orientación respecto de alguna iglesia.

25 Expresamente lo consagra el art. 2 de la Ley No 133 de 1994 ("Estatutaria de Libertad Religiosa"). "Ninguna Iglesia o Confesión religiosa es ni será oficial o estatal. Sin embargo, el Estado no es ateo, agnóstico, o indiferente ante los sentimientos religiosos de los colombianos. El Poder Público protegerá a las personas en sus creencias, así como a las Iglesias y confesiones religiosas y facilitará la participación de éstas y aquéllas en la consecución del bien común. De igual manera, mantendrá relaciones armónicas y de común entendimiento con las Iglesias y confesiones religiosas existentes en la sociedad colombiana".

26 Por ejemplo, las Fiestas de San Francisco de Asís en Quibdó, Chocó, y las Fiestas de San Pedro en el Huila. 
El criterio que ha servido para evaluar la adecuación constitucional de normas que de alguna forma promueven una determinada confesión, le otorgan beneficios o privilegios, o la vinculan con los organismos del Estado, radica más que en su carácter de confesión mayoritaria o numerosa en la comunidad, en el hecho de que se pueda verificar la práctica como manifestación cultural. La naturaleza laica del Estado no se contrapone, entonces, con la reivindicación de principios propios de las diversas doctrinas religiosas que tienen asiento en la sociedad. De la sentencia C-766 de 2010 se puede extractar un test o prueba de laicidad de una política o medida, como es el hecho de que su fundamento sea secular, de suerte que su contenido religioso deberá ser meramente anecdótico o accidental. En adición, el apoyo estatal a una determinada política o medida con contenido religioso no viola los deberes generales de laicidad consagrados en la sentencia C-152 de 2003 si es posible determinar un sentido fuertemente cultural 27 .

Colombia no es atea ni indiferente a las creencias religiosas. De hecho, la protección a la libre expresión de las creencias religiosas se observa también en algunos delitos que consagra el Código Penal, tales como la violación a la libertad religiosa, el impedimento y la perturbación de ceremonia religiosa o los daños o agravios a personas o cosas destinadas al culto. El Estado no profesa ninguna religión. La restricción no está entonces en la práctica libre de una religión, sino en el trato inequitativo a favor de una sola por parte de los organismos del Estado o a la vulneración de la neutralidad al vincularse con determinada práctica religiosa que no tenga igualmente naturaleza cultural. La Corte desde el principio de su jurisprudencia ha declarado la importancia de respetar la exteriorización efectiva de las distintas convicciones religiosas mediante, entre otros, publicaciones e implementación de centros educativos o de difusión de sus principios, que permitieran no sólo dar a conocer, sino también enseñar el valor particular de su doctrina para la ordenación de la sociedad y la orientación de la vida humana.

La única interpretación válida del artículo $2^{\circ}$ constitucional ${ }^{28}$ es que el Estado respeta por igual toda creencia practicada por las personas independientemente

\footnotetext{
27 En Estados Unidos hay un test, denominado Lemon, que ayuda a decidir cuáles acciones o medidas gubernamentales violan la separación entre el Estado y la Iglesia consagrada en la Primera Enmienda. Conforme al test las normas o acciones estatales: deben contar con un propósito secular, no pueden tener el efecto principal de hacer avanzar o reprimir la religión y no pueden derivar o resultar en una "excesiva implicación gubernamental" con la religión. Su nombre se debe a que se adoptó en el fallo de la Corte Suprema, Lemon v. Kurtzman, de 1973. Véase Alley (1999).

28 "Son fines esenciales del Estado: servir a la comunidad, promover la prosperidad general y garantizar la efectividad de los principios, derechos y deberes consagrados en la Constitución facilitar la participación de
} 
del sentido en el que se expresen. Es factible que haya algún tipo de relación de cooperación con todas las iglesias y confesiones religiosas por la trascendencia inherente a ellas mismas (sentencia C-088 de 1994). Sólo en el entendido del respeto a la igualdad en todos los órdenes resulta admisible otorgar tratamientos jurídicos favorables a iglesias y confesiones religiosas. Las diferentes iglesias deben tener igual oportunidad de participación en instancias de decisión, igual autonomía y oportunidad de brindar enseñanza religiosa en establecimientos públicos o privados, así como iguales beneficios tributarios y aquellos de la objeción de conciencia al servicio militar. De la línea jurisprudencial se deriva igualmente que las iglesias tienen el derecho a decidir si entablan relaciones con el Estado.

La laicidad estatal es una garantía para respetar los principios que sustentan el Estado social y democrático de derecho, fundado en la dignidad de la persona y de conformidad con el respeto por la igual oportunidad de participación en las decisiones que afectan a la comunidad (sentencia C-1175 de 2004). La garantía a valores constitucionales como la tolerancia y la pluralidad implican que no se le puede brindar a una determinada confesión, por mayoritaria que sea, una mayor oportunidad participativa para imponer su visión y el valor de su doctrina sobre la oportunidad de participación de cualquier otra confesión. Ningún organismo estatal puede interceder a favor de la mejoría en las condiciones de difusión de una determinada religión. Hay un deber, entonces, hacia la no promoción o patrocinio de alguna confesión (sentencia C-766 de 2010).

Sobre la no interferencia de la iglesia en la orientación de la política pública, pero también sobre la interferencia del Estado en la regulación de las prácticas de cada confesión, conviene señalar que no sólo los laicos o ateos, sino también los creyentes, deben defender el principio de laicidad. En el Estado Constitucional de Derecho ni se pueden tomar decisiones jurídicas o políticas públicas que favorezcan a una determinada confesión religiosa, ni se pueden fundamentar decisiones o políticas en las creencias o los dogmas religiosos. La educación y la medicina son orientadas por la ciencia, no por la superstición o la fe. La salud pública, en vez de la razón privada propia de la confesionalidad, orienta la educación sexual y reproductiva.

todos en las decisiones que los afectan y en la vida económica, política, administrativa y cultural de la Nación defender la independencia nacional, mantener la integridad territorial y asegurar la convivencia pacífica y la vigencia de un orden justo. Las autoridades de la República están instituidas para proteger a todas las personas residentes en Colombia, en su vida, honra, bienes, creencias, y demás derechos y libertades, y para asegurar el cumplimiento de los deberes sociales del Estado y de los particulares". 
El principio de laicidad no sólo protege a los organismos del Estado de la indebida injerencia religiosa, sino también a las religiones de la interferencia del poder en la difusión de su fe. Cuando el emperador Constantino convirtió al cristianismo en la religión oficial del Imperio, en el siglo IV, la afectó en lugar de beneficiarla debido a que la espiritualidad y el compromiso con la justicia, propios de la enseñanzas de los profetas y del mismo Cristo, fueron sustituidas por el compromiso con el poder (West, 2004). El constitucionalismo colombiano reformuló radicalmente el diseño público-institucional de la Regeneración, en tanto movimiento político e ideológico que sustentó la proclamación y el desarrollo de la Constitución de 1886, estableció a la religión católica como de la Nación. Como recuerda la sentencia C-350 de 1994 desde los mismos debates al interior de la Asamblea Nacional Constituyente, se planteó que la referencia a Dios en el Preámbulo era una invocación compatible con la pluralidad de creencias religiosas y no el llamado a un Dios o un credo en particular. La entrada en vigencia (sobre todo jurisprudencialmente) de la Constitución de 1991 introdujo una reforma radical del régimen establecido en la Constitución de 1886 respecto de la concepción del Estado y su relación con las distintas iglesias. En 1991 se optó por la laicidad, como alternativa a la consagración católica de la nación colombiana, en tanto opción jurídico-política que sustenta un principio distinto a la confesionalidad como modelo ideológico. Se acogió en consecuencia, desde la consideración de la importancia del pluralismo, la libertad religiosa.

En este contexto habría que objetar la ofensiva conservadora en la configuración del derecho constitucional colombiano. Así, intérpretes periodísticos de la Constitución han sostenido que, debido a la invocación a la protección de Dios en el preámbulo, es un texto teísta. Esta alusión a Dios, de un lado, tiene un carácter general y no se refiere a una iglesia en particular y, de otro, no consagró confesional al país sino que expresó, de conformidad con el artículo 19, que las creencias religiosas son un valor constitucional protegido (sentencia C-350 de 1994).

Muchas discusiones jurídicas y políticas surgen por interpretar selectiva y acomodaticiamente alguna disposición constitucional, la cual se toma de manera aislada de otras disposiciones y, sobre todo, sin consideración de los pilares ideológicos en los que se estructura el texto constitucional establecidos en el Preámbulo, los principios y en el catálogo de derechos. El método interpretativo histórico, conforme al cual el significado de la Constitución debe extraerse del mismo sentido con el cual fue redactada por los constituyentes, presenta una elemental dificultad. Toda vez que la Constitución fue redactada por un cuerpo colegiado de diversas e incluso divergentes tendencias políticas e ideológicas, resulta imposible reconstruir el sentido de alguna disposición apelando a la voluntad del constituyente 